\title{
Blood Pressure Excursion
}

National Cancer Institute

\section{Source}

National Cancer Institute. Blood Pressure Excursion. NCI Thesaurus. Code C126365.

Instances where blood pressure is outside of established parameters. 